\title{
EFFect of A Back School Protocol on the ReFERRAL RATE OF PATIENTS WITH LOW BACK PAIN TO AN Industrial Physiotherapy CliniC
}

\begin{abstract}
Back schools are educational programmes originally developed in a work place (Volvo factory in Sweden) for patients with back pain, to enable them to manage their own back problems better. 'Back school' was originally aimed at modifying the behaviours of patients with low back pain (LBP), with the view to prevent relapses. In an effort to encourage and stimulate the use of 'back school' among health workers in Nigeria, this study was designed to evaluate the efficacy of a back school protocol in a Soap Making Industry in Lagos, Nigeria.

One hundred and ten (110) workers of a Soap Making Industry in
\end{abstract}

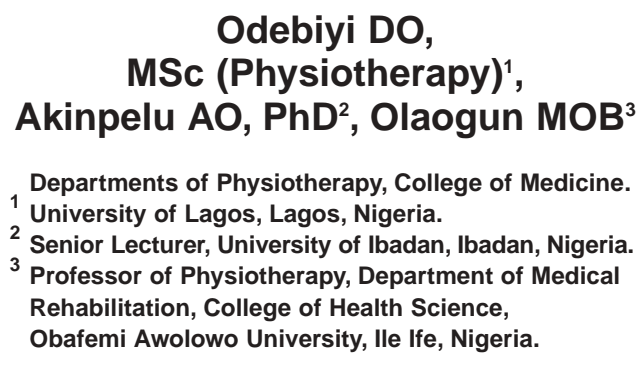

2 Senior Lecturer, University of Ibadan, Ibadan, Nigeria.

${ }^{3}$ Professor of Physiotherapy, Department of Medical Rehabilitation, College of Health Science, Obafemi Awolowo University, Ile Ife, Nigeria. Lagos, Nigeria, participated in this study. A pre-test, post-test experimental design was employed. The participants were divided into two groups - office workers and factory workers for the purpose of the training in the content of the back school protocol. The 'back school' consisted of classroom teaching and the use of two videotapes titled "lifting technique" and "back pain". Data on demographic information, knowledge of back structures and back care were collected using a questionnaire with closed ended questions, which was completed before, immediately after and 8 weeks after the administrations of the contents of the back school protocol (Akinpelu and Odebiyi, 2004). The records of the factory's clinic were also reviewed for the 12-months before and 12 months after the study.

The mean values of the participants' age, height, weight and body mass index (BMI) were $36.60 \pm 9.10$ years, $1.65 \pm 0.10 \mathrm{~m}$, $69.13 \pm 7.70 \mathrm{~kg}$ and $25.40 \pm 3.30 \mathrm{~kg} / \mathrm{m}^{2}$ respectively. The results showed that the 12-months prevalence of low back pain (LBP) among the workers was $71 \%$. The result also showed that over $50 \%$ of the participants never had any information or lesson on back care, and those that had some form of information obtained it by chance. There was $23 \%$ reduction in referral for care of back pain 12 months after the administration of the back school protocol. However, Chi square analysis showed that there was no significant difference $(p=0.23)$ between the number of physiotherapy referrals to the factory's clinic 12-months before the study and 12-months after the study

The findings of this study suggest that the back school protocol was able to impart some knowledge (of back pain and back care) in the industrial workers. This knowledge seems to have assisted this group of individuals to cultivate good postural habits, particularly at work. This might have led to the $23 \%$ reduction in the reported cases of patients with LBP to the factory's Physiotherapy Clinic.

\section{KEY WORDS: LBP, BACK SCHOOL PROTOCOL, PHYSIOTHERAPY REFERRAL, WORK PLACE.}

\section{INTRODUCTION}

Back school is a conservative form of a therapeutic intervention in the management of mechanical low back pain (LBP). Back school was originally developed to educate patients with LBP to be able to manage their own back problem (Zachrisson - Forssel, 1980; Borensteen and Wisel, 1989). However, modern back schools have advanced into other areas today - of not only managing pain but also preventing injury to the back that can precipitate back pain. The first back school - The Swedish Back School, was developed in 1969 in a Volvo factory in Sweden and was initially meant to treat workers with back injuries (Zachrisson - Forssel, 1980). Traditionally, back school includes discussions on back anatomy, biomechanics, proper lifting techniques, pain control, stress management and exercises (Difabio, 1995; Hall and Hadler, 1995). However, back school has been presented in various forms in terms of aims, content and administration; this to an extent, is usually to reflect the underlying philosophy of the organizers and the population they serve, as back schools are developed in conformity with the culture of the country concerned (White, 1983; Apts, 1996). Back Schools have been so successful that in Scandinavia there are now over 300 of them, and variations of the Swedish model of back school exist in North America, Australia and the United Kingdom (Haynes, 1984). The wide spread use of back school has

\section{CORRESPONDENCE TO:}

D.O. Odebiyi

Department of Physiotherapy,

College of Medicine,

University of Lagos

PMB 12003, Nigeria

Tel: (234) 08024717968

Email: femiodebiyi@yahoo.com 
been suggested to be connected with the high cost of back injury, the lack of a single effective treatment, and the evidence that patient with back pain exhibits some behavioural risk factors (Daltoy et al, 1997).

According to Twomey and Taylor (1994), the impact of various work place factors in the aetiology and occurrence of back pain is incomplete. The risk associated with lack of knowledge in relation to work demand cannot, therefore, be over emphasised. Thus, the adequacy of communication and education is of considerable value, both in the prevention of onset and recurrence of back pain. Wallner - Schlotfeldt and Stewart (2000), in their study identified some of the factors that are associated with the development of back pain in the work place. These factors include; bending to do work near the floor, lifting objects from the ground and participation in heavy manual work. Weak trunk or abdominal muscles, (rectus abdominis and external and internal oblique abdomini muscles) also predispose to back pain (Wallner - Schlotfeldt and Stewart, 2000).

The postures adopted during activity and developed over a period of time appear to have a major association with the presence of back pain (McKenzie, 1990; Twomey and Taylor, 1994). Studies have demonstrated that the appearance of pain is only an indication that one has assumed a poor posture (Mckenzie, 1981 and Apts, 1996) and once back pain has developed, poor posture will perpetuate or worsen the problem (Mckenzie,1990). With the overall programme of risk control, employee education has been shown to reduce lost work time (Tabor, 1982). This has led researchers like Bullock (1990) and Apts (1996) to advocate for the prevention of back pain in the work place. The major aim of this present study was to determine the effects of a back school protocol on the referral rate of patients with back pain to a work place clinic. It was conducted as a one year follow - up of a previous study (Akinpelu and Odebiyi, 2004).

\section{METHODOLOGY}

The study was conducted at the factory clinic of a Soap Making Industry in Lagos, Nigeria. Included in the study were 110 workers (60 factory workers and 50 office workers), this was made up of all the workers of the factory except a few who were on their annual leave during the study period. Three industries were approached. However, permission to carry out the study was granted by the authority of only one industry, and because of the logistics involved in having to stop production, the BSP training was presented as part of the company's 'safety week' (a period when workers are instructed on the various safety measures as it concerns the nature of their job). An overtime allowance was paid by the industry's management as incentive.

The content of the BSP is shown in Table 1. The detail of the training procedure and mode of the presentation of the BSP was taken from Akinpelu and Odebiyi (2004) who studied 'The Development and Effects of a Nigerian Back School Model on Industrial Workers' Knowledge of Back Pain and
Back Care. They concluded that the back school model was able to improve the industrial workers' knowledge of back pain and back care. In order to encourage the practice of the safety techniques learned from the BSP, the 'safety manager' of the factory was specially trained as a 'train the trainer'. He was charged with the responsibility of encouraging continuous practice of the corrected postures often assumed by the participants during the discharge of their normal daily duties, particularly at the work site.

A review of the work place Physiotherapy Clinic Records was done 12 months before and 12 months after the administration of the BSP. This was done so as to be able to determine and compare the prevalence (12 month prevalence) of LBP among the workers 12 months before and 12 months after the administration of the BSP. The number of patients' visits to the Physiotherapy Clinic as a result of back

Table 1: The element of the Back School protocol training Programme.

\section{THE BACK SCHOOL PROTOCOL:}

\section{Consists of education and exercise elements}

EDUCATION ELEMENT: cognitive and demonstration sessions Cognitive Sessions:

- Simple anatomy of the spine

- Epidemiology of low back pain

- Common causes of low back pain

- Biomechanics (functions) of the spine.

Demonstration Sessions:

- Good and bad postures at work and rest

- Safe lifting and handling

- Use of video tapes (Myers, 1989; Wakefield Health Authority,1979).

\section{EXERCISE ELEMENT:}

- Stretching exercises

- Strengthening exercises

- Toning exercises

\section{REINFORCEMENT:}

- Training of 'safety manager' of the factory/work place as "work-site trainer"

- Work-site trainer to further encourage continuous practise of good postures, particularly at the work site.

- Handbook (pamphlet) and posters - containing illustrative diagrams.

- Observation of workstations, followed by review with the safety manager.

TEACHING METHOD:

Classroom method - first the factory workers, then the office workers. The training programme was introduced into the 1999 safety week programme of the company, and overtime allowance paid by management served as incentive. 
pain or injury was extracted from the Clinic's records for the periods 12 months before and 12 months after the training in the BSP.

\section{STATISTICAL METHOD}

Data analysis including descriptive statistics was done using statistical package for solution services (SPSS). Significant difference between occurrence of LBP prior to and after intervention was determined using chi square statistics. Value of $\mathrm{p}<0.05$ was taken as the level of significance.

\section{RESULTS}

\section{Participants:}

One hundred and ten (110) industry workers (males 93 and females 17) participated in the study, 60 of whom were factory workers and 50 were office workers .The mean age, height, weight and BMI were $36.60 \pm 9.10$ years, $1.65 \pm 0.10 \mathrm{~m}, 69.13 \pm 7.70 \mathrm{~kg}$ and $25.40 \pm 3.30 \mathrm{~kg} / \mathrm{m}^{2}$ respectively. Ninety five point five percent $(95.5 \%)$ of the participants were full time employees and they worked for between 8 -12 hours per day. The mean number of years spent on the job (work experience) by the participants was $8.00 \pm 6.50$ years.

\section{Back Care Knowledge:}

More than $50 \%$ of the participants had never had any lesson or information on back care, those that had some form of information obtained it by chance; either during their visit to the factory's clinic for treatment or during occasionally organised seminar.

\section{Occurrence of LBP:}

The Majority $(71 \%)$ of the participants reported a previous history of LBP. Table 2 shows the number of physiotherapy referrals to the factory's clinic 12 months before and 12 months after training in the BSP. In the year preceding the study, the total number of Physiotherapy referrals to the clinic because of LBP was 39 while there were 29 referrals to the Physiotherapy clinic 12 months after the study. Chi square statistical analysis showed that there was no significant difference $(\mathrm{p}=0.23$ ) between the number of physiotherapy referrals to the factory's clinic 12 months before the study and 12 months

Table 2: Physiotherapy referral to the factory's clinic 12 months before and after the administration of Back School.

\begin{tabular}{|c|c|c|c|c|c|c|}
\hline & \multicolumn{2}{|c|}{$\begin{array}{c}\text { Physiotherapy } \\
\text { referral } \\
\text { before study }\end{array}$} & \multicolumn{2}{|c|}{$\begin{array}{l}\text { Physiotherapy } \\
\text { referral } \\
\text { after study }\end{array}$} & \multirow[t]{2}{*}{$\mathrm{X} 2$} & \multirow[t]{2}{*}{ 'p' value } \\
\hline & $\mathbf{n}$ & $\%$ & $\mathrm{n}$ & $\%$ & & \\
\hline $\begin{array}{l}\text { Physiotherapy } \\
\text { referral }\end{array}$ & 39 & 36 & 29 & 26 & 1.47 & 0.23 \\
\hline
\end{tabular}

Figure 1: Sources of information of the participants about back education.

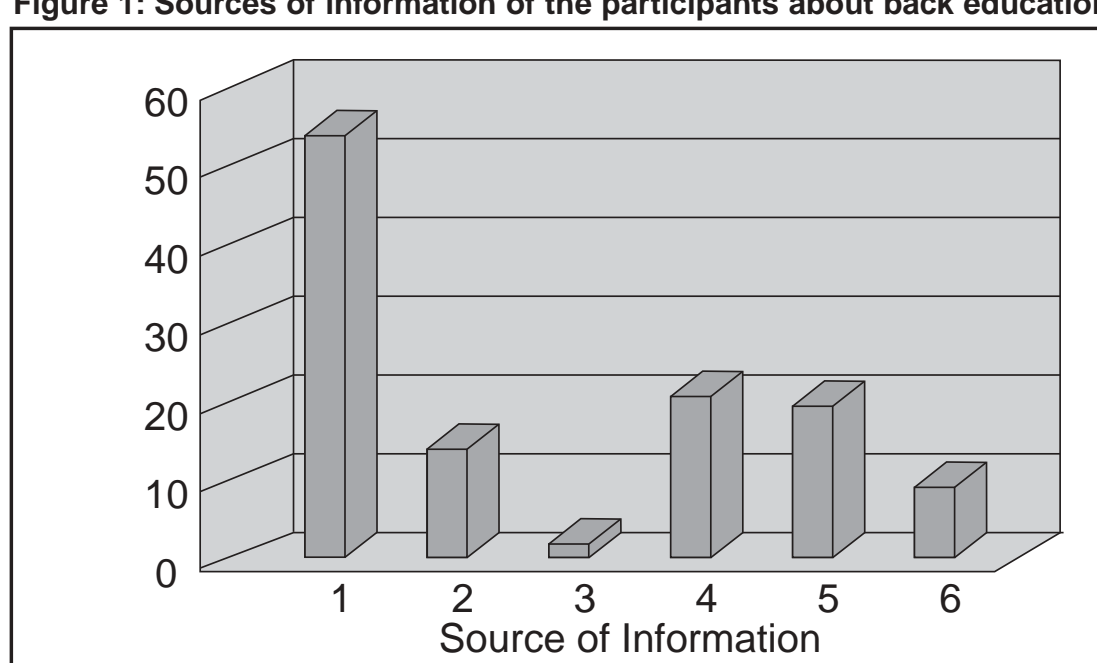

\section{Series 1}

KEY: 1 - No formal education, 2 - Print media, 3 - Communication media, 4 - Company's clinic, 5 - Seminar, 6 - Friends after the study, however, there was $23 \%$ reduction in referral for care of back pain 12 months after the administration of the back school protocol.

\section{DISCUSSION}

This study was a one year follow-up study of an earlier study which attempted to develop a Nigerian model of the "Back School" (Akinpelu and Odebiyi, 2004). Back school is a rehabilitation treatment for back pain, it is an educational programme that requires the individual with back pain to undergo an educational message and motivate them to modify their behaviour to prevent relapses (Bonaiut and Fontanella, 1996). Hence the focus of 'back school' is to involve patients with back pain in the management of their own back problems (Difabio, 1995). The results of this study provided a fair test of the ability of back care education in the form of back school to limit LBP in an industrial setting. The study showed that back care education may have a place in reducing LBP, to some extend, in a work place, as there was a twenty three percent $(23 \%)$ reduction in physiotherapy referral of patients with back pain to an industrial physiotherapy clinic 12 months after the administration of the back school protocol. However, this reduction was not statistically significant. Apts (1996) in his study of railway workers reported a twenty percent $(20 \%)$ reduction in back injury after these workers was taken through the American Back School.

The twenty three percent (23\%) reduction in the referral of patients with back pain to the factory's Physiotherapy Clinic after the administration of the back school protocol (BSP) suggests that the industrial workers might have benefited from the back school training programme. The beneficial effects of the BSP suggested in this study can be further enhanced by the increase in the industrial workers' knowledge after the administration of back school reported in a previous study by Akinpelu and Odebiyi (2004). Akinpelu and Odebiyi (2004) in their study 'Nigeria back school model: development and effect on industrial workers' knowledge of back pain and back care' concluded that the Nigerian model of a back school improved the industrial workers' knowledge of back pain and back care. The 
newly gained knowledge could have led to an increase in the awareness of proper handling of the back and self care and thereby motivated participants to modify their behaviour during the discharge of their daily duties particularly at work. Thus, fulfilling one of the major aims of back school which is to involve patients with back pain in the management of their own back problem (Difabio, 1995). This finding agrees with the findings of an earlier study by Bergquist - Ullman (1997), who studied the efficacy of a 'back school' in Swedish factory employees and reported that Swedish factory employees with LBP who attended 'back school' had significantly fewer sick - leave days during their initial pain episode than did those in a placebo treatment.

\section{CONCLUSION}

The reported high prevalence of LBP in this group of participants 12 months before the administration of the back school protocol might be because these participants were inadequately informed about back pain and the care of the back, particularly in the proper handling of the back (figure 1).

The findings of this study suggest that the back school protocol was able to impart some knowledge (of back pain and back care) in the industrial workers which seems to have assisted them to cultivate good postural habits, particularly at work. The authors believe that the newly acquired knowledge might have helped the industrial workers to cultivate good postural habits and empowered them in the proper handling of the back. This might be responsible for the reduction in physiotherapy referral of patients with back pain to the factory's physiotherapy clinic 12 months after the administration of the back school protocol. Thus formal back care education in the form of back school should form part of the management strategies for patients with back pain, particularly as a preventive measure. This, we believe justified the need to develop a back school that will take into consideration relevant cultural practices in Nigeria.

\section{REFERENCES}

Akinpelu OA, Odebiyi DO 2004 Nigeria back school model: development and effect on industrial workers' knowledge of back pain and back care, African Journal of Medicine and Medical science. 33:201-205

Apts D 1996 Back injuries prevention handbook. Lewis publishers, Chelsea, USH Pp 88-96

Berquist-Ullman M, Larson U 1977 Acute low back pain in industry, Acta Orthropaedica scandinavica. (suppl 170): 73

Bonaiut D, Fontanella G 1996 The Affective Dimension of Low Back Pain: Its influence of the outcome of Back School, Achieves of Physical Medicine and rehabilitation. 77(12):1239-1242

Borensteen DG, Wisel SW 1989 Low Back pain Medical diagnosis and comprehensive management, Saunders Philadelphia. Pp 10-25
Bullock MI 1990 Ergonomics: A broad challenges for the physiotherapists. In Bullock MI (Ed) Ergonomics. The physiotherapists in the workplace, Churchill, Livingstone Edinburgh. p3

Difabio R 1995 Efficacy of comprehensive rehabilitation programmes and back school for patients with low back pain- a Meta analysis, Physical Therapy. 75 (10):865-878

McKenzie RA 1981 The Lumbar spine: mechanical diagnosis and therapy. Spinal Publication, Walkanae, New Zealand. p25

McKenzie RA 1990 Treat your own back. Spinal Publications, Lower Hutt, New Zealand pp15 -16

Myers B 1989 Back Pain: The common and serious conditions and therapy. British Medical Television, Video Health Publication, VH 0004

Tabor M 1982 Reconstructing the scene: Back Injury, Occupational Health and Safety. February 16

Twomey LT, Taylor JR 1994 Physical Therapy of the low back pain. Churchill, Livingstone. Second Edition p 10

Wakefield Health Authority 1979 Lifting without stress. Postgraduate Medical Centre Pinderfields Hospital Audio - visual Unit, Tape no VT 032

Wallner-Schlotfeldt PJ, Stewart A 2000 The predisposing factors to low back pain in workers, South African Journal of Physiotherapy. 56 (3):33-38

White AH 1983 Back school and other conservation approaches to low back pain. St Louis, Mosby pp 1-15

Zachrisson - Forssell M 1980 The Swedish Back School, Physiotherapy. 66:112-116. 


\title{
HeALTh EdUCATION NEEDS AMONG INDIVIDUALS WITH LOW BACK PAIN
}

\begin{abstract}
Lack of positive results from many of the health-education programmes for patients with low-back pain (LBP) is possibly due to the type of health information that may have been presented and the method that had been used. The present study sought to explore health-education needs among individuals with LBP. A qualitative approach that utilised in-depth interviews and a focus-group discussion was used. Data was drawn from ten participants attending physiotherapy treatment due to a non-specific LBP at the Nairobi Hospital Rehabilitation Unit, using purposive sampling. A thematic analysis procedure was used to analyse the data. The study found the participants' health education needs to be incongruent with the medical professionals' assumptions of what the patients' health education needs were. Deficiencies in explanation of the cause, diagnosis, prognosis, and the appropriate use of health services were found. The findings suggest that a more encompassing model of health education was believed to be more fitting. Since the findings indicate that the individuals with LBP require health education on various aspects, a Rehabilitative Model of health education was probably more pertinent to the individuals. That way, a more encompassing, all-inclusive model of health education would cover on the aspects that were currently neglected.
\end{abstract}

KEY WORDS: BACK PAIN, HEALTH EDUCATION, PATIENTS, NEEDS.

\section{INTRODUCTION}

Due to the multifactorial nature of lowback pain, efforts aimed at preventing and managing the prevalence of the condition has proven mostly unsuccessful. Effective treatment of low-back pain is indeed embraced by substantial difficulties (Linton and van Tulder 2001, Harland and Lavallee 2003). This has led to the existence of many therapeutic and health-education approaches (Moseley 2002). As a result, several guidelines (protocols) have been developed to provide a template for more effective clinical practice on low back pain management (Bigos et al 1994, Li and Bombardier 2001). Although the guidelines recommend patient education as a means of limiting some of the problems experienced by the patients suffering from low back pain (Bigos et al 1994), none has been found to be a model for these patients.

CORRESPONDENCE TO:

Nyagah Julius Ng'uurah,

Rehabilitation Unit,

Nairobi Hospital

P.O Box 30026-00100

Nairobi Kenya

Email: jnnyagah@yahoo.com.

Tel: +254 (722) 700949

$+254(020) 2714400$
Furthermore, for some time now, there has been a consensus of opinion that there was no clinically-significant achievement of health-education programmes for low-back pain (Cohen et al 1994). Additionally, reviews of education-based 'back' schools provide convincing evidence that patient education has failed to effect any positive changes on low-back pain sufferers (Koes et al 1994). However, the latest evidence implies that the lack of positive effects in many of the health-education programmes was probably due to the type of education that had been presented to patients and the methods used to present the information (Mosley 2002). The health education that has mostly been presented to patients has always been planned, designed, and implemented by the medical professionals without their taking into consideration the views and opinions from the consumers of this information (Axelsson et al 1995). For example, written patient education has always been based on the medical professionals' assumption of what patients needed to know. These assumptions have frequently been shown to be incompatible with the patients' actual needs (Axelsson et al 1995, Coulter et al 1998).

Since physiotherapists work principally within a biomedical paradigm, health is seen as an absence of disease, while affective or cognitive parameters of health are usually ignored (Richardson and Eastlake 1994). This assumption obviously neglects other aspects that evidence has proved as influencing the development and sustenance of LBP. Psychosocial, economic, environmental, and occupational aspects among others do play a role in influencing the development and sustenance of LBP. When these aspects are ignored during health education sessions, it could possibly result in LBP progressing into the chronic stage. In addition, the Medical Model of health education had failed to take into consideration the individuals' needs that were likely to influence negatively LBP during the management of the problem. This approach views LBP as a predicament of the individual, clearly caused by a disease, trauma, or other health situations requiring therapeutic care provided only in the form of the patient's treatment medically, surgically, or physically by the professionals (WHO 2001). Published research on low-back pain has similarly utilised the biomedical model of tissue dysfunction that focuses on disease and tissue pathology rather than on illness (Bardin 2002) or on the problems individuals experience as they manage 